\title{
Ergonomic hazard identification of workers engaged in brick making factories
}

\section{K umkum Pandey* and Aditi Vats}

Department of Family Resource Management, Govind Ballabh Pant University of Agriculture and Technology, Pantnagar263145 (Uttarakhand), INDIA

*Corresponding author. E-mail: kumkum.pandey.unique@gmail.com

Received: March 3, 2013; R evised received: J une 25, 2013; Accepted: J uly 15, 2013

\begin{abstract}
This study was done with the aim to identify the specific ergonomic risk factors in the workplace affecting the both male and female workers while doing raw brick making activities and to analyze the pain/discomfort related to it. Twenty male and twenty female workers from the raw brick making unit were randomly selected and a detailed ergonomic risk factors were analyzed with the help of NIOSH Ergonomic Hazard Identification checklist. The questions were based on the primary job responsibility of the workers. Data revealed that nearly 8 percent males and 10 percent females were in 'usually' category, 25 percent males and 28 percent females in 'sometimes' and approximately 18 percent male and 13 percent females who never performed the task were kept in the category 'never'. It was found that all the male and female workers usually require exerting force with their hands and used the hand tools to do the task. About 8 percent males and 5 percent females were usually, 15 percent male and only 10 percent female were sometimes and 28 percent males and 35 percent female were never stood continuously for a period of more than 30 minutes. On the whole all the male and female respondents were lifting or lowering the objects between floor and waist height or shoulder height and most of the workers were becoming exposed to the vibration while performing the task and they were carrying the weight more than $50 \mathrm{lb}$. The study indicates that the majority of the activities are in the high risk category and demands immediate ergonomic intervention in the form of tool, workstation and process design.
\end{abstract}

Keywords: Brick factories, Ergonomics hazards, Musculoskeletal disorders, Workplace repetition

\section{INTRODUCTION}

Nearly 20 percent of injuries and illness in the workplace and nearly 25 percent of the annual worker's compensation payment are attributed to back injuries which are related to musculoskeletal disorders (Bureau of Labor Statistics, 1993). As work-related musculoskeletal disorders (WRMSDs or WMSDs) have been defined by Barr and Clark (2004) as the injuries or disorders of the tendons, muscles, nerves, joints, cartilage, and spinal discs associated with exposure to risk factors in the workplace. Work-related musculoskeletal disorders do not include injuries or disorders caused by slips, trips, falls, motor vehicle accidents, or similar accidents. MSD represent nearly one-third of all injuries and illnesses requiring days away from work, a trend that has remained relatively unchanged over the past five years. The nature of MSD injuries - also known as ergonomic injuries - is far more severe than a typical injury. Representing 29 percent of all injuries in 2010, MSD injuries led to 11 median days away from work, compared with 8 for all days-away-from-work cases, according to a Bureau of Labor Statistics ( 2010). The rate of MSD injuries per 10,000 full-time workers was 34 that is an increase of less than 0.1 percent from the incidence rate of 117 in 2009.

ISSN : 0974-9411 (Print), $2231-5209$ (Online) All Rights Reserved @ Applied and Natural Science Foundation www.ansfoundation.org
MSDs are a significant public health problem today, due to their high impact on disability, personal suffering, absence from work and the direct and indirect costs to the health care system. According to the statistics of the Global Burden of Diseases which has been developed by the World Health Organization (WHO), MSD contributes $37 \%$ of the disease burden which is attributable to occupational risk factors (W.M.S. Johnson et al. (2011). The risk factors for developing work-related musculoskeletal disorders include individual factors (e.g. inadequate strength, poor posture), physical requirements at the workplace (e.g. work requiring high force, prolonged awkward static posture, highly repetitive work, use of vibrating tools), and organizational and psychosocial factors (e.g. prolonged work hours, poor work-rest cycle, shift work, low job security, little social support) (Marras et al., 2009).

In this regards the science of ergonomics seeks to adapt the job and workplace to the worker by designing task and tools that are within the worker's capabilities and limitations. So it is clear that a tremendous number of workers are routinely exposed to physical hazards and many of them develop one or more serious work related musculoskeletal disorders during their working lifetime. The prevalence of these has increased dramatically in 
developing countries and it is exposed to be much worse due to inadequate safety system, lack of awareness, lack of training of occupational safety and health and lack of ergonomic standards and epidemiological studies.

The Occupational Health and Safety Act (1989) clearly state that the general duty of all employers is to provide their employees with a workplace free from recognized serious hazards. This includes the prevention and control of these hazards. The incident and severity of musculoskeletal disorders and other workplace injuries and illness in the industry demand that effective programs be implemented to protect workers from these hazards.

Brick factory workers, who spend most of time in factories, are at greatest risk. They perform different activities manually and mechanically. Mainly the work includes cutting raw bricks, extracting clay, digging clay, crushing and/or grinding clay, mixing clay, carrying clay, shaping the bricks, loading bricks in and out of the kiln, loading bricks onto the truck, loading bricks in and out of the brick wheelbarrow, pulling a brick wheelbarrow, arranging bricks to dry. These are various tedious jobs in their workplace. All these jobs are physically demanding and involve the main risk factors because of repetitive motion, heavy physical workload and excessive body motion which can result in high risk of back injuries, neck, shoulders, arms, and upper limbs.

Besides this, the main risk factors can be associated with upper limb work-related musculoskeletal disorders because of repetitiveness, high frequency of action, excessive force, awkward posture, insufficient recovery time, use of mechanical tools, and exposure to high temperature. Space limitation requires workers to use much uncomfortable posture like standing, stooping, squatting, stretching, reaching, bending and twisting during the activities. It can be classified as "Moderately heavy" work because of energy expenditure is more in these activities.

The brick factory is interesting to be determined in this current study because the nature of the work the consisted of several work-related risk factors. For example, most workers had to work with repetitive movement, and sustain the same posture for the whole day; lifting the products in awkward postures, and work with contact pressure at the hand and wrist areas. Consequently, the workers in this factory may increase the number and severity of work-related injuries. The aim of the present study was to assess the ergonomic hazards prevailing in their workplace and is to create a work environment that recognizes and accommodates a variety of human capabilities and limitations in a manner that reduces the potential for MSDs. Most people agree that removing an identified ergonomic hazard from the workplace would be ideal, but it is not always technically or economically feasible to do so. Instead, administrative controls (e.g., training or job rotation) are often necessary to reduce the likelihood of ergonomic-related injuries.

\section{MATERIALS AND METHODS}

In the present study five brick factories, which were twenty percent of the total factories, were purposively selected in the Pura block of Faizabad district in Uttar Pradesh, India and simply purposive random sampling was used to select the study area and workers. For descriptive data sample size of forty (twenty male and twenty female) was selected which was eight percent of the total population i.e. 500. Most of the male and female workers were from the 31-45 years of age and they were performing the raw brick making task more than 11 hours per day which is not permissible.

This study was done to identify the ergonomic hazards in the workplace greatly affecting the workers by using NIOSH (National Institute of occupational safety and Health). The questionnaire consisted of a series of objective questions with never, sometime; and usual responses.

\section{RESULTS AND DISCUSSION}

Ergonomic hazard identification: On the ergonomic hazard identification checklist the questions were based on the primary job responsibility of the workers. The answers were divided into three groups, in which responses were given in terms of never, sometimes and usually. When the workers are not exposed to the condition then responses were kept under the category of never. When the worker is exposed to the condition less than three times daily such types of workers kept under the group of sometimes. When the workers exposed to the condition for more than three times then it was categorized as usually.

The workers from the selected unit were doing hard work. Data revealed that nearly 8 percent males and 10 percent females were in 'usually' category, 25 percent males and 28 percent females in 'sometimes' and approximately 18 percent male and 13 percent females were never performed the task and externally paced were kept in the category 'never'.

It was found that all the male and female workers usually require exerting force with their hands. Data revealed that all respondents usually used the hand tools or handle part or objects for performing their task. None of the respondents never and sometimes used the hand tools or handle parts. In this concern Hagberg et al. (1995) considered that the local mechanical pressure can lead to the onset of the musculoskeletal problems and direct mechanical pressure on the tissues may be due to poorly designed tools and handles.It was found that near about 8 percent males and 5 percent females were usually, 15 percent male and only 10 percent female were sometimes and 28 percent males and 35 percent female were never 


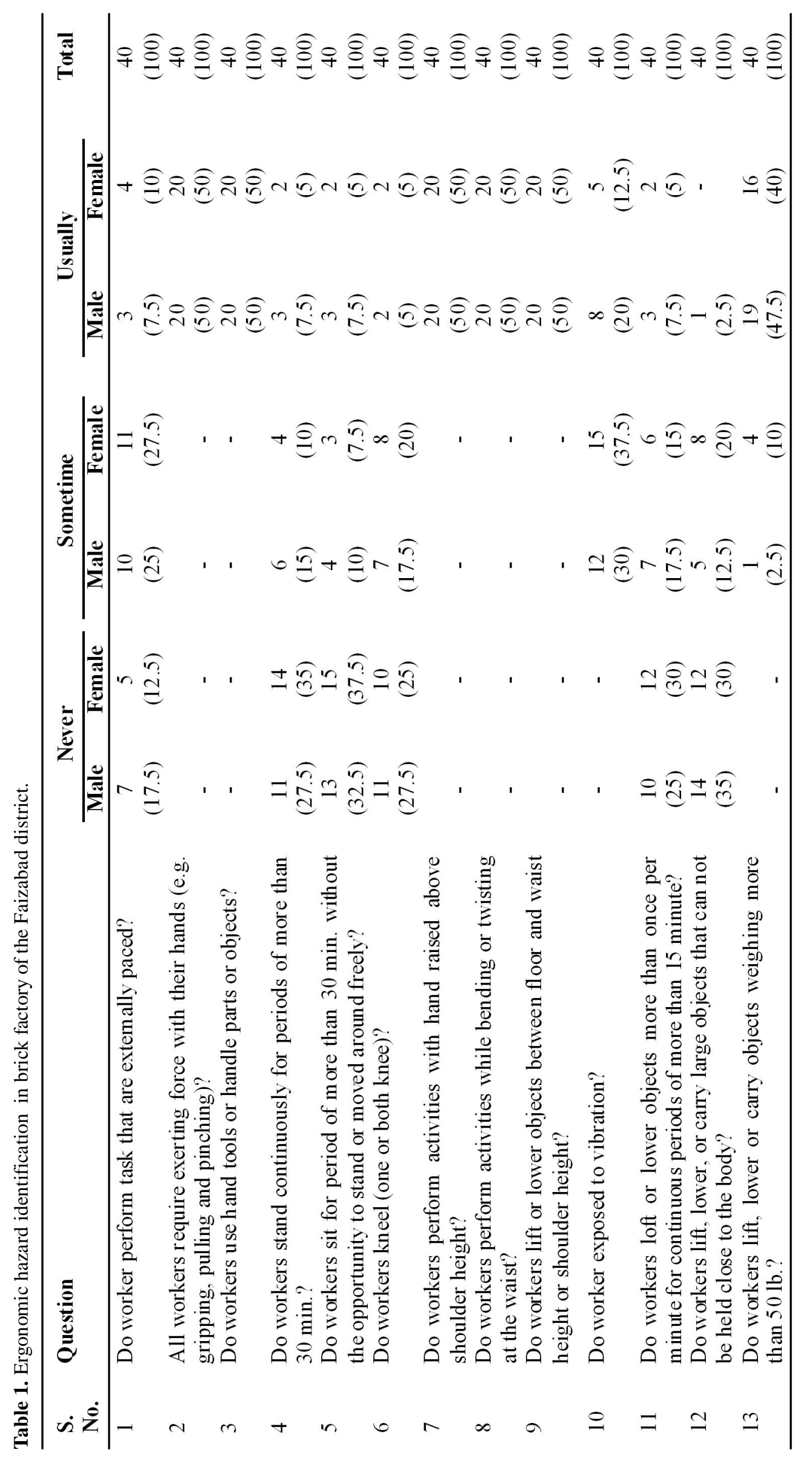


standing continuously for the period of more than 30 minutes. Dul et al. (1991) attempted to develop a work/ rest model that could be used for various static postures based upon maximum holding time. However, Mathiassen and Winkel (1992) indicated that exercise protocols, a muscle group, position, and coordination could affect the work/ rest time in addition to the various postures in the Dul model.

It was reported that nearly 8 percent males and 5 percent females usually, 10 percent males and 8 percent females sometimes, up to 33 percent males and 38 percent females never sit for a period of more than 30 minutes without the opportunity to stand or moved around freely.

Overall results revealed that 5 percent males and females usually, near about 18 percent males and 20 percent females sometimes in a day, 28 percent males and 25 percent females never kneel while performing the task. All the respondents of the male and female category said that they usually performed the task with hands raised above shoulder height and while bending or twisting at the waist.

On the whole, it was found that all the male and female respondents were lifted or lowered the objects between floor and waist height or shoulder height. Data revealed that 20 percent males and nearly 13 percent female were usually, 30 percent male while 37.5 percent females were sometimes in a day and none of the respondent from male and female category were never exposed to vibration while performing the task. Palmer, et al., (2006) and Griffin (2006) reported that the occurrence of vibration syndrome is related to the duration of vibration exposure types of work processes and types of tools used and the main adverse health effects are disorders of the lumbar spine and the connected nervous system.

It was found that up to 8 percent males and only 5 percent females were usually, 18 percent males and 15 percent females were sometimes and 25 percent males and 30 percent females were never lifted or lowered objects more than once per minute for continuous periods of more than 15 minutes.

Approximately 3 percent males and none of the females were usually, 13 percent males and 20 percent females were sometimes in a day and 35 percent males and 30 percent female respondents were never lifted, lowered or carried large objects that could not be held close to the body.

Nearly about 48 percent males and 40 percent females were usually, only 3 percent male and 10 percent female workers sometimes and none of the workers never, lifted, lowered or carried objects weighing more than $50 \mathrm{lb}$.

\section{RECOMMENDATIONS}

Provide mechanical aids (e.g., arm and wrist rests) for employees that do repetitive work.

Incorporate task rotation

Modify the work load required of the individual in a particular time frame

Provide gloves to the employees that improve their grip on the object

Reduce the working load, reducing stress to various body parts

Incorporate rollers and powered belt conveyers to move material

Utilize handles to make it easier to grip items

Utilize proper tools for impact or striking activities

Avoid tasks that require the individual to lean on wrists, elbows, or the abdomen

Provide cushioned tool grips

Ensure that the workstation, tool design, and tool shape are such that it will allow the worker's body to maintain an unstrained and comfortable position

\section{Conclusion}

It can be concluded that most of the workers felt the various work related problems because of presence of various ergonomic hazards like improper designing of tools, workplace, and manual material handling, lifting and lowering the load. There is an urgent need of designing and development of tools, equipments, workplace workstations, prevention programme and training to be conducted at the specific level that can minimize the ergonomic risk factors in the workplace and workers can be benefited from it as well as may improve health and productivity.

\section{REFERENCES}

Barr, Barbe and Clark. (2004). Work-related musculoskeletal disorders of the hand and wrist: epidemiology, pathophysiology and sensorimotor changes. J ournal of Orthopaedic and Sports Physical Ther apy, 34 (10):610-627.

Bureau of Labour Statistics. (1993). Evaluating and improving world activities. current problems of Work Science. Sozialistiche F orstwirtschaft, 38 (5):137-139.

Bureau of Labour Statistics. (2010). U. S. Department of Labour. News release. November 8, 2012.

Hagberg, M., Silverstein, B.A. and Wells, R.V. (1995). Work related musculoskeletal disorders; A reference for prevention; Kuorinka I and Forcier L (eds) London; Taylor and Francis. 1995:556.

Marras, W., Knapik, G. and Ferguson, S. (2009). Lumbar spine forces during manoeuvring of ceiling-based and floor-based patient transfer devices. J ournal of Ergonomics, 52(3): 384397.

The Occupational Safety and Health Act. (1989). Official Gazette, Supplement, 1989-03-13, No.11, Vol. 12, p.2336.

Johnson, W.M.S., Bertha, A. and Priscilla, J. (2011). Prevalence of upper extremity musculoskeletal disorders among workers in an industrial town in Tamilnadu. J ournal of Clinical and Diagnostic Research, 5(2):187-190. 
Palmer, K.T., Haward, B., Griffin, M.J., Bendall, H. and Coggon, D. (2006). Validity of self reported occupational exposures to hand transmitted and whole body vibration. Occupational Environmental M edicine, 57:237-241.

Griffin, M. J., Howarth, H.V.C., Pitts, P.M., Fischer, S., Kaulbars, U., Donati, P.M. and Brereton, P.F. (2006) 'Guide to good practice on whole-body vibration: non-binding guide to good practice for implementing Directive 2002/44/EC on the minimum health and safety requirements regarding the exposure of workers to the risks arising from physical agents (vibrations)', Brussels, Belgium.

Dul, J., Douwes, M. and Smitt, P. (1991). A work-rest model for static postures. In: Queinnec, Y., Daniellou, F. (Eds.), Design for Everyone; Proceedings of the 11th IEA Congress. Taylor \& Francis, London, pp. 93-95.

Mathiassen, S. and Winkel, J. (1992). Can occupational guidelines for workrest schedules be based on endurance time data? Ergonomics, 35 (3): 253-259. 